\title{
Lo que los personajes tienen que decir. La creación de diálogos mediante la metodología de William Layton
}

\section{Resumen}

La creación de diálogos es una fase esencial de la escritura de guiones audiovisuales. Este artículo explica el sistema de análisis de textos dramáticos de William Layton, originalmente dirigido a la interpretación actoral, y lo aplica a la escritura de diálogos audiovisuales. También expone cómo se ha formado en este sistema a estudiantes de un Máster de guion y muestra su utilidad para la creación de diálogos a través de una encuesta a 85 alumnos de diferentes promociones. De ellos, el 59\% tenía formación o experiencia previa en el audiovisual. Antes de conocer el método Layton, solo un $9 \%$ de la muestra manejaba otra técnica para crear diálogos y un 50\% conocía consejos genéricos que guiaran el diseño de las conversaciones de sus personajes. $Y$ es que las monografías técnicas o académicas sobre guion no ofrecen metodologías sistemáticas que permitan al aspirante a guionista iniciarse en la escritura de diálogos, solo presentan recomendaciones. Con la difusión de esta técnica para la creación de diálogos audiovisuales, este artículo pretende contribuir a evitar que esta carencia de metodologías sistemáticas se traslade a los programas formativos. Los encuestados confirman que este método favorece la síntesis $(84 \%)$, la planificación previa de los diálogos y la funcionalidad de cada frase de los personajes $(91 \%)$, permitiendo que estas se adecuen mejor a su caracterización psicosocial (94\%) o momento del arco dramático (95\%). Un $85 \%$ de los encuestados sigue empleándola, una vez terminada su formación, en su vida profesional como guionista o declara transmitirla en sus clases cuando trabaja como docente.

\section{Ignacio Nevado}

Doctorando en Comunicación Audiovisual, Publicidad y Relaciones Públicas. Universidad Complutense de Madrid, España.

Correo electrónico: joseneva@ucm.es ๑ orcid.org/0000-0002-5027-219X

Google Scholar

Laura Fernández-Ramírez

Doctora en Comunicación

Audiovisual.

Profesora, Universidad Internacional de La Rioja, España. Correo electrónico:

laura.fernandezramirez@unir.net ๑ orcid.org/0000-0003-4196-9136 Google Scholar

\section{Adrià Naranjo}

Doctorando en Comunicación Audiovisual.

Universidad Internacional de La

Rioja, España.

Correo electrónico:

adria.naranjo@unir.net

๑ orcid.org/0000-0002-4869-4617

Google Scholar

Recibido: enero 29 de 2021

Aprobado: junio 23 de 2021

Palabras clave:

alfabetización audiovisual, diálogos, experiencia didáctica, guion, William Layton. 


\section{What characters have to say. The creation of dialogues using William Layton's methodology}

\begin{abstract}
Dialogue creation is an essential phase of audiovisual scriptwriting. This article explains William Layton's dramatic texts analysis system originally aimed at acting performance, and applies it to the writing of audiovisual dialogues. It also explains how students of a Master's degree in screenwriting have been trained in this system and shows its usefulness for creating dialogues by means of a survey applied to 85 students from different classes. Of these, 59\% had previous training or experience in audiovisuals. Before learning about the Layton method, only $9 \%$ of the sample used other techniques to create dialogues and $50 \%$ knew generic advice that would guide the design of their characters' conversations. The fact is that technical or academic monographs on screenwriting do not offer systematic methodologies that allow aspiring screenwriters to get started in dialogue writing, but they only provide recommendations. By disseminating this technique for the creation of audiovisual dialogues, this article aims to help prevent this lack of systematic methodologies from being transferred to training programs. Participants confirm that this method favors synthesis (84\%) and pre-planning of the dialogues and the functionality of each sentence of the characters $(91 \%)$, allowing them to better adapt to their psychosocial characterization (94\%) or moment of the dramatic arc (95\%). Eighty-five percent of the respondents continue to use it in their professional life as scriptwriters after completing their training or state that they pass it on in their classes when they work as teachers.
\end{abstract}

Key words:

audio-visual literacy, dialogues, script, teaching experience, William Layton. 


\section{Introducción}

Iniciarse en la escritura de guiones audiovisuales es un proceso complejo. No solo es necesario tener una idea, sino también estrategias creativas con las que concretarla artísticamente. Cuando uno se inscribe en una escuela de cine o Máster Universitario, espera encontrar metodologías o técnicas que permitan iniciarse en esta labor, hasta que choca en los primeros días de clase con cierta frustración ante la falta de patrones fijos que poder aplicar. La escritura de guiones tiene más de artesanía que de industria fordiana. Y es que las estrategias creativas que pueden transmitirse vienen definidas por años de ejercicio profesional en el marco de la industria cinematográfica y televisiva, pero no existen fórmulas ni recetas magistrales que poder aplicar a cualquier tipo de producto o historia y que garanticen su resultado. Los manuales de guion ofrecen orientaciones generales que lo facilitan, pero se construyen como libros de autoayuda que sirven para moldear las tendencias creativas y adaptarlas a las demandas de la industria con la finalidad de estandarizar el medio (Conor, 2014).

Dominar el arte de escribir diálogos resulta fundamental en el cine. Orson Welles aconsejaba "empezar por lo que dice el personaje antes de verle actuar (...) aunque el cine sea esencialmente visual se llega a las imágenes a partir de la solidez de las palabras, ya que son básicas para la construcción de imágenes" (en Estrin, 2002, p. 102; traducción propia). Pero lograr esto no es fácil para el recién llegado. Los manuales técnicos de guion audiovisual priorizan la trama por encima de cualquier otro elemento (Greens, 2017). Continúa, a fin de cuentas, la tendencia aristotélica de destacar la estructura de las acciones por encima de otros elementos de la tragedia. Si para Aristóteles (1999) la fábula precedía en importancia al carácter, pensamiento o elocución del personaje (Poética, 1450b), los tratados de guion abordan fundamentalmente cuestiones de estructura o caracterización de personajes. Como Aristóteles, 
que subraya el recurso a la metáfora en la elocución de los personajes como muestra del talento del artista (Poética, 1459a), grandes gurús del guion como Snyder (2018) o Seger (2019) reconocen la trascendencia del diálogo, y en particular de su subtexto (Seger, 2017), pero no ofrecen técnicas específicas para su creación. El diálogo tampoco es objeto de ningún capítulo del célebre manual de Syd Field (2005) pese a que de entre sus páginas se deduzca su importancia radical para hacer avanzar la historia, comunicar hechos e información al lector, revelar a los personajes, establecer las relaciones entre estos, darles realismo, naturalidad y espontaneidad, revelar los conflictos de la historia, de sus protagonistas, sus estados emocionales o comentar la acción. Los diálogos parecen haber caído en explicaciones superficiales "que ahora están tan arraigadas en la industria de Hollywood que son simplemente de sentido común" (Conor, 2014, p. 128; traducción propia).

Pese a ocupar la mayor parte de un guion, los diálogos no tienen un lugar destacado en la bibliografía cinematográfica. Yves Lavandier (2011) destaca la trascendental misión del diálogo para la caracterización de personajes y sus relaciones, para la comunicación de sus pensamientos, deseos o experiencias, y para hacer avanzar la acción. Sin embargo, le dedica apenas 15 páginas de las 537 que componen su manual. Michel Chion (2009) dedica al diálogo tan solo cuatro páginas en las que enfatiza en la necesidad de que este sea dinámico, realista y que se amolde a la caracterización del personaje y la situación en la que se encuentra. Solo Robert McKee, que no había incluido un capítulo específico sobre diálogo en su famoso Story, Substance, Structure, Style and the Principles of Screenwriting (2013), convirtió el diálogo en el objeto central de uno de sus manuales -Dialogue. The Art of Verbal Action for Page, Stage and Screen (2018)—. Sin embargo, en él tampoco aporta una metodología o técnica para su escritura, sino consejos centrados en la caracterización de personajes, la creación de subtexto o la credibilidad que ya se han mencionado en otros casos. John Truby (2014) es uno de los pocos 
autores que ofrece un acercamiento a la escritura del diálogo mediante una ficha en la que aborda el arco del personaje, sus problemas, las estrategias que desarrolla para resolverlos, el deseo, el punto final, el adversario, el conflicto y el giro o revelación.

En los casos en los que la literatura académica se ha centrado en el diálogo lo ha hecho principalmente desde el campo de la sociolingüística y no desde los estudios fílmicos (Piazza, 2010; Richardson, 2010). El foco de estos trabajos está en la capacidad del diálogo para transmitir ideologías concretas de un modo efectivo (Moulton, 2019), en el análisis del efecto que tienen según qué discursos en la sociedad y en su función didáctica (Capuzza y Spencer, 2017), en la manera en la que se capturan y su valor para el análisis (Casetti y Di Chio, 2007) o en el impacto que tiene en su relación con el público y en la evolución de los géneros cinematográficos (Bednarek, 2015). Los estudios cinematográficos o televisivos atienden a los cambios que han sufrido los diálogos ante la Tercera Edad de Oro de la televisión, adecuándose al tono general de las obras y siendo más cuidados (Imre, 2012; Winter, 2016). Destacan el abandono del diegetic retelling — la tendencia de las soap operas a recordar por diálogo sucesos ya acontecidos en la trama- (Mittell, 2010; Hoff, 2016) mediante el recurso a la superposición de las réplicas (Brook, 2009) o el naturalismo (Mittell, 2015; Jaagola, 2019). Solo algún estudio se adentra en el proceso creativo y genera una clasificación sobre el tipo de información que pueden trasladar los diálogos (Kozloff, 2000) o prioriza su escritura por encima de otras cuestiones como la estructuración del relato (Greens, 2017).

El presente artículo ofrece una metodología que ayuda al estudiante de guion en la creación de secuencias de conflicto, las que poseen una mayor carga dramática y en las que la psicología de los personajes cobra mayor protagonismo. Esta metodología parte de la necesidad de planificar y estructurar los diálogos de antemano para adecuar las intervenciones de los personajes a una serie 
de funciones narrativas que traducen de forma implícita la caracterización psicológica del personaje al tiempo que este avanza en la solución de una situación dramática determinada. Sirve también como sistema de autoanálisis, ya que permite al estudiante valorar si en la escena se incluyen intervenciones accesorias, explicativas, poco ajustadas al carácter del personaje o al momento del arco dramático en el que se encuentra.

\section{Método}

A semejanza del artículo "Writing-for-The-Cut: What Can Screenwriters Learn from film Editors about Storytelling?" (Loftin, 2018), este trabajo se inspira en un proceso sistemático diseñado para el trabajo en otro ámbito artístico (en este caso la interpretación actoral) y lo adapta a la escritura de guiones. Se parte de que la información visual de un guion apela fundamentalmente al trabajo de dirección y puesta en escena posterior, y que con el diálogo un guionista apela fundamentalmente a los actores (Ryan, 1991). Por ello, se ha considerado que un método de autoanálisis como el de William Layton (2016), destinado al trabajo del intérprete podía ser de utilidad para la creación de diálogos. Si durante su escritura se tienen en cuenta cuestiones que serán necesarias para el trabajo actoral posterior, esto redundará en un mejor resultado tras su rodaje.

Esta metodología para la escritura de diálogos se incorporó en 2017 a la formación de guionistas del Máster Universitario en Creación de Guiones Audiovisuales de la Universidad Internacional de La Rioja (UNIR). La falta de técnicas o metodologías sistemáticas que transmitir para abordar la creación de diálogos llevó a adecuar esta metodología procedente del campo de la interpretación a la formación en guion en la asignatura de Construcción de Personajes. Los resultados de los estudiantes fueron muy positivos, tanto en la escritura de sus escenas como en su satisfacción al término del curso. 
Para valorar la utilidad de su aprendizaje se envió, el 12 de enero de 2020, una encuesta a 120 estudiantes egresados. El estudio que aquí se incluye atiende a los 85 egresados que respondieron a la encuesta. Se les consultó sobre su nivel formativo y experiencia en el campo del guion previos a su ingreso en el Máster, sobre su conocimiento anterior de alguna metodología para la escritura de diálogos, sobre su percepción de la utilidad de este sistema para: a) trabajar la síntesis de los diálogos y secuencias, b) considerar que cada frase debe tener una función para caracterizar al personaje o para dotar de mayor interés dramático a la secuencia, c) mejorar su empleo del subtexto y evitar las intervenciones accesorias y explicativas, d) contribuir a la caracterización del personaje y a focalizar la escena en el punto del arco dramático en el que se encuentra, y e) encontrar palabras precisas para cada intervención y caracterizar e individualizar mejor a los personajes mediante los matices de su habla. Por último, se les consultó sobre los beneficios obtenidos de la práctica de creación de diálogos propuesta dentro de la experiencia formativa y sobre si siguen empleando el método Layton en la escritura de diálogos en su vida profesional posterior a la finalización de sus estudios.

\section{Un método para guiar al actor; un método para enseñar a hablar al personaje}

El sistema Stanislavski, que inspira el método Layton al que aludiremos a continuación, fue la primera sistematización del trabajo actoral y fundó la corriente del realismo psicológico. El trabajo de Stanislavski fue fundamental para el desarrollo de otras metodologías teatrales de este corte (Meyerhold, Vajtangov y M. Chéjov). Su reformulación en Estados Unidos por parte de Strasberg, Adler y Meisner adaptó estas enseñanzas personalizando distintos métodos y llevando su aplicación a la interpretación cinematográfica, aprovechando el realismo psicológico que permitía alcanzar a sus actores. Los métodos de Strasberg, Adler y Meisner parten de un trabajo previo de análisis del texto, donde el actor debe buscar el subtexto intrínseco a cada 
palabra del guion, ya que debe justificar cada acción, reacción o emoción de su interpretación mediante la existencia de alguna palabra o frase que acuse la motivación, objetivo, intención o estado interior del personaje (Pérez, 2009).

El método desarrollado por William Layton a partir de las enseñanzas de Stanislavski plantea una serie de categorías de análisis que permiten al actor entender el 'aquí y ahora' del personaje, atendiendo a lo que este vive en una escena concreta y a los procesos psicológicos que subyacen a sus palabras. El objetivo de su adaptación a la creación de diálogos es que su formulación ya tenga en cuenta lo que el intérprete requiere de ellos. Que actor y guionista compartan las mismas categorías de análisis contribuirá a un desarrollo e interpretación orgánicos de las emociones y pensamientos del personaje, por ello se explican estas a continuación.

\section{Protagonista, antagonista y deseo}

Una secuencia de conflicto se define porque en ella dos personajes presentan posiciones contrarias ante la petición de un deseo por parte del protagonista de la escena. El protagonista no tiene por qué ser el personaje principal de una obra, ni el que protagonice otras escenas, sino el que, en ese momento determinado, tiene una necesidad importante y urgente que resolver con otro personaje. Eso que el protagonista necesita 'aquí y ahora' del antagonista es lo que se denomina deseo. En torno a esto se plantea la situación de conflicto de esa escena determinada. Por lo tanto, al trasladar este sistema a la escritura del guion, a la hora de planificar su escena esto será lo primero que debe plantearse el autor: qué necesita el protagonista de la escena 'aquí y ahora'. El deseo debe suponer la variación del status quo: la situación establecida para los personajes al inicio de la escena. Esto es clave para centrar al escritor en el punto del arco dramático en el que se encuentran los personajes. 
Una vez establecido el statu quo, el punto de partida de la escena, es sencillo establecer qué personaje desarrolla un rol protagónico y cuál ocupa el papel antagónico. Para aclarar más esta cuestión, resulta pertinente atender al origen etimológico de los términos 'protagonista' y 'antagonista'. Ambos proceden de la raíz griega agón, que significa desafío, contienda, disputa o conflicto. El protagonista es, por tanto, aquel que se posiciona a favor de la disputa, que provoca el conflicto que interrumpe el statu quo. Por su parte, el antagonista es el personaje que quiere conservar el statu quo, mostrándose por tanto reticente a las demandas del protagonista. Esta lucha de intereses vertebra y motiva la acción de la escena, que avanzará a través del desarrollo de las estrategias que los personajes utilicen para conseguir el deseo, o negarlo, según corresponda.

\section{Razones para pedir o negar}

Siguiendo esta metodología, lo siguiente que se plantean actor y escritor son las razones que tiene cada personaje para pedir o negar el deseo. El protagonista tendrá razones para pedir y el antagonista razones para negar. Cada razón debe clasificarse según estos tres parámetros:

\section{a) Razones abiertas, secretas o inconscientes}

En primer lugar, las razones de uno u otro personaje pueden ser abiertas, secretas o inconscientes. Un personaje usa una razón abierta cuando no tiene nada que ocultar sobre sí mismo, sus intenciones o sobre los demás. En este caso, su motivación puede ser conocida por su interlocutor sin perjuicio para él. La verbalización de su razón para pedir o para negar puede ser, de hecho, la mejor estrategia para sus fines. 
La razón es secreta cuando al personaje le interesa ocultarla. Es decir, la razón es conocida por el personaje y secreta para el interlocutor y/o el resto de los personajes. En estos casos, el personaje oculta su motivación porque exponerla puede serle contraproducente. El personaje intentará desplegar otras estrategias que le permitan conseguir su fin. Las razones secretas pueden acabar saliendo a la luz por descuido, por deducción de otro personaje o como última medida posible para el personaje si se le agotan el resto de estrategias.

Por último, la razón se considera inconsciente cuando es secreta también para el propio personaje. La razón inconsciente es conocida por el autor y también es conocida y manejada por el director y el actor. Puede, incluso, ser conocida por el espectador, pero nunca por el personaje. A pesar de ser desconocidas por el personaje (traumas, recuerdos borrados...) condicionan su comportamiento. El personaje puede descubrirlas en un momento dado y, debido a su fuerte intensidad, al salir a la luz provocan una fuerte reacción en él.

\section{b) Razones emocionales, prácticas o de principios}

Las razones para pedir o negar de los personajes, que pueden ser abiertas, secretas o inconscientes, deben a su vez clasificarse atendiendo a la naturaleza de esas motivaciones: se distingue así entre razones emocionales, prácticas o de principios.

Las razones emocionales son aquellas que vienen motivadas por emociones, sentimientos o pasiones. Las razones prácticas responden a cuestiones funcionales, objetivas. En este caso, la necesidad de conseguir o negar el deseo no está influida por los sentimientos. Por último, hay un tipo de razones denominadas de principios que responden a la creencia en un tipo de conducta interiorizada por el personaje como correcta u obligatoria. Se trata de razones motivadas por cuestiones como la fe, la tradición, los principios personales, las normas sociales o de un grupo, la ética, la ley o ideología del personaje. 
c) Razones egoístas, altruistas y por el bien de todos

Además de clasificar las razones según su carácter explícito o consciente y según su naturaleza, se han de clasificar atendiendo a quién beneficia esa decisión de pedir o negar algo. Así, las razones pueden ser egoístas cuando el personaje actúa en su propio beneficio. O pueden ser altruistas cuando lo hace en beneficio de otra persona (el protagonista puede, incluso pedir el deseo en favor del antagonista o este puede negar por el propio bien del protagonista). La razón es también altruista cuando se pide o niega en beneficio de una tercera persona. Por último, existe la posibilidad de que el personaje pida o niegue por el bien de todos, apelando así al bien común.

\section{Clasificación de las razones}

Cada razón para pedir o negar se describe, por tanto, con tres atributos, uno perteneciente a cada una de las categorías descritas, existiendo así múltiples combinaciones posibles (Tabla 1). De este modo, una razón puede ser abierta, emocional y altruista; o bien puede ser abierta, práctica y por el bien de todos; o bien secreta, emocional y egoísta, etc.

Cada personaje tendrá al menos una razón para pedir o para negar, pero también puede combinar dos, o incluso los tres tipos de razones. Es decir, un personaje puede tener una razón abierta, detrás la cual oculte una razón secreta. E incluso podría tener, en el fondo, una tercera razón inconsciente, que fuera el verdadero motor de su acción, sin él saberlo.

Cada personaje está definido por sus propias razones y ambos personajes no han de resultar simétricos. Uno puede tener una razón abierta y otra secreta, mientras que el otro puede presentar solo una razón abierta. 
Tabla 1. Tipos y modos de clasificación de las razones

\begin{tabular}{ll}
\hline Protagonista & Antagonista \\
\hline Razón para pedir & Razón para negar \\
\hline $\begin{array}{l}\text { Abierta, secreta o inconsciente } \\
\text { Emocional, práctica o de principios }\end{array}$ & $\begin{array}{l}\text { Abierta, secreta o inconsciente } \\
\text { Emocional, práctica o de principios } \\
\text { Egoísta, altruista o por el bien de todos }\end{array}$ \\
\hline
\end{tabular}

Fuente: elaboración propia.

Las razones permiten así caracterizar psicológicamente al personaje a muchos niveles. Primero sobre su grado de extroversión, capacidad para la manipulación o el tipo de relación que mantiene con su interlocutor. También, pueden alertar sobre la presencia de un trauma a superar. Su naturaleza puede indicar el carácter, sensibilidad, ética o ideología del personaje; y la consideración sobre el beneficiario de su objetivo permite ver el grado de solidaridad, empatía, egoísmo o generosidad de este. La predominancia de unos tipos de razones u otras en un mismo personaje irá ligada a un tipo de personalidad. Las múltiples combinaciones posibles facilitan enormemente la variedad en la caracterización de diferentes personajes y marcar el punto en el que se encuentran dentro de su arco de transformación. Introducir esta carga informativa de forma indirecta en el marco de una conversación sobre un tema específico, contribuye a trabajar el subtexto del diálogo, dotándolo de mayor interés y profundidad dramática. Esta búsqueda de matices psicológicos favorece también la atención a las palabras escogidas por cada personaje, asegurando así su individualización mediante un habla diferenciada. Al mismo tiempo, la escritura de diálogos mediante las distintas combinaciones de razones y las diversas estrategias apropiadas a cada fin, garantizan la coherencia de los personajes a lo largo de toda la obra, tanto en su discurso como en sus acciones. 


\section{Estrategias}

Otra forma de caracterización psicológica son las estrategias que emplean los personajes para conseguir o negar el deseo. Cada uno de ellos tendrá un acercamiento diferente para lograr su objetivo. Su modo de abordarlo dirá mucho de su forma de ser, su grado de inteligencia emocional, su madurez, su capacidad de planificación o su carácter impulsivo. Para conseguir o negar el deseo, cada uno articulará diferentes pasos de su plan mediante sucesivas líneas de diálogo. Así, cada estrategia se desarrollará mediante diferentes intervenciones de un personaje, esto resulta fundamental, dado que el éxito de un plan se fundamenta en gran medida en su articulación temporal. Una estrategia alcanzará intensidad dramática y permitirá profundizar en la psicología del personaje si tiene protagonismo y desarrollo en la escena. Lógicamente, también se podrá optar porque un personaje cambie de estrategia durante la misma. Esto hablará de su impulsividad, su inseguridad o dará a entender su limitada capacidad de reacción ante el plan del otro o su poca habilidad para la manipulación.

\section{Estado de ánimo y relaciones}

El resto de categorías que termina de describir a los personajes e influye en su discurso son el estado de ánimo y la relación que existe entre ellos o con el lugar en el que se desarrolla la situación.

El estado de ánimo de cada uno de los personajes debe deducirse de sus intervenciones para mostrar indirectamente su posicionamiento emocional en ese punto de la narración. El estado de ánimo del personaje condiciona sus estrategias e influye en la intensidad de sus razones para pedir o negar. El estado de ánimo, además, conecta la acción con los antecedentes. El personaje arranca la escena con un estado de ánimo que depende de 
lo que le haya ocurrido justo antes de su encuentro con el otro personaje. Reflejar ese estado de ánimo en sus líneas de diálogo ayuda al guionista a centrar la escena en el punto del arco dramático en el que se encuentre cada personaje, así como a preocuparse por la diferenciación del habla de cada uno.

Por otro lado, el tipo de relación que exista entre los personajes determinará también su modo de hablar. En este sentido, William Layton distingue entre dos niveles de relación: relación social y relación emocional.

La relación social responde al vínculo objetivo que une a los personajes: son amigos, vecinos, padre-hijo, profesor-alumno, jefe-empleado, o incluso son desconocidos. La relación social influye en los diálogos estableciendo, por ejemplo, la jerarquía o los equilibrios de poder, o marcando el nivel de discurso que han de desarrollar los personajes.

La relación emocional, por su parte, es la variante subjetiva del vínculo entre los personajes y, a diferencia de la anterior, es distinta para cada uno de ellos y evoluciona a lo largo de la obra, lo que hace al guionista tener que prestar atención al arco dramático.

La relación emocional atiende a lo que un personaje significa para el otro 'aquí y ahora', qué es lo que le hace sentir, o cómo lo percibe. Puede ser alguien querido, alguien temido, puede ser un modelo a seguir o puede representar todo aquello en lo que no quiere llegar a convertirse.

Como se ha dicho, la relación emocional no solo es distinta para cada uno de los personajes, sino que puede además variar en las distintas escenas o evolucionar a lo largo de la obra. Un personaje que en un momento dado es percibido para el otro como alguien odioso, puede en otro momento darle lástima o parecerle ridículo. La relación emocional responde, por lo tanto, 
a lo que la otra persona despierta en el personaje en ese punto del arco dramático y en esa situación concreta. Al tratarse de una percepción personal y subjetiva, esta relación emocional es muy propicia a expresarse en términos figurados, especialmente cuando los personajes lo expresan verbalmente. Así, cuando Clarice Starling conoce a Hannibal Lecter en la famosa escena de El silencio de los corderos (The Silence of the Lambs, Demme, 1991), el psiquiatra se refiere a ella como 'pajarito', señalando así subtextualmente su relación emocional. Su relación social es 'agente del FBI - reo psicópata', pero al emplear el apelativo 'pajarito' Lecter da a entender cómo la percibe él, cómo se siente ante ella, con una enorme carga connotativa de superioridad y desprecio hacia la agente. Clarice a su vez, deja ver su visión de Lecter mediante una frase: "no, usted se los comía", transmitiendo el desprecio que siente hacia caníbales como él.

Del mismo modo, el lugar en el que se desarrolla la acción influye en todos los aspectos del discurso, tanto en la forma como en el contenido. Por un lado, el valor contextual del espacio marca el aspecto formal del diálogo y condiciona los tipos o cantidad de estrategias a desarrollar en relación a las circunstancias dadas (hace que los personajes tengan que hablar en voz baja si están en una iglesia o una biblioteca, les obliga a guardar las formas en un velatorio, a apresurarse en la puerta de un tren a punto de partir o dificulta su entendimiento en mitad de una discoteca). Mas allá de eso, existe una relación con el lugar que responde al vínculo emocional que el personaje tiene con el espacio, por lo que resulta aún más relevante a nivel de caracterización psicológica de los personajes. Al igual que ocurría con la relación emocional entre personajes, la relación con el lugar es personal y subjetiva para cada personaje y responde a lo que el propio espacio provoca en ellos en ese justo momento (al ser subjetiva, la relación con el lugar también es mutable). Este vínculo emocional con el espacio en que transcurre la escena influye de manera determinante en el estado de ánimo del personaje y en sus estrategias y razones. Es muy distinto cómo se desarrolla un diálogo para un personaje si 
se encuentra en un lugar cómodo para él, familiar, por el que siente cariño o si necesita imperiosamente abandonar ese espacio o luchar por mantenerlo. El lugar puede dar miedo, cohibir, fortalecer, traer recuerdos, motivar, desmotivar o incluso doler físicamente al personaje. El vínculo que tengan con el espacio donde transcurre el conflicto puede beneficiar claramente a uno u otro personaje, incluso formando parte de sus estrategias (citar al otro ahí, irse, destruirlo, etc.).

\section{Resultados}

\section{Experiencia didáctica}

Esta acción docente de instruir a los estudiantes de guion en el método Layton, se inicia una vez se han trabajado principios básicos de caracterización (motivación, objetivo, conflicto externo, conflicto interno, etc.) y otras técnicas para definir los personajes como la ficha, el arco de transformación y la caracterización por acciones o imágenes metafóricas. También, se han explicado anteriormente las recomendaciones genéricas de los manuales más reconocidos sobre la materia. Posteriormente, se introducen las categorías de análisis de William Layton que acaban de ser descritas (Tabla 2). 
Tabla 2. Categorías y fases de análisis del Método Layton

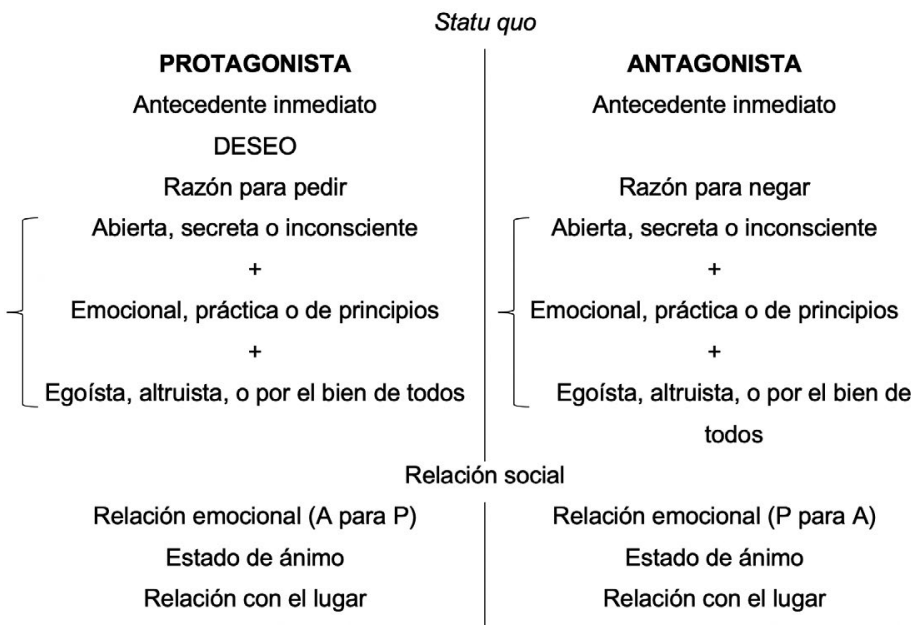

Fuente: elaboración propia.

Para facilitar su explicación se recurre al visionado de una escena. Se aporta el guion de la escena transcrito, y esta se analiza grupalmente, guiados por el profesor. Se puede optar por realizar este procedimiento en más de una ocasión para propiciar el dominio de las categorías de Layton. Resulta idóneo aplicar este sistema de análisis a escenas diferentes, de largometrajes y de series de televisión, de drama y comedia, ya que así los alumnos pueden apreciar el diferente ritmo de diálogo, uso del subtexto y habla en los distintos formatos y géneros. 
El docente comienza el análisis guiado con el visionado de la escena. Después, atendiendo al guion transcrito, plantea la necesidad de localizar en él una intervención que permita determinar el deseo, esa necesidad de cambiar el statu quo y que determinará el protagonismo de la escena. Los estudiantes definen así quién actúa como protagonista y quién como antagonista en este caso dado. Localizan también información relativa al antecedente inmediato, que les permite corroborar quién es el que quiere modificar la situación. Los estudiantes deben ir marcando en el texto la frase que sirva a la expresión del deseo.

A continuación, el docente pide que identifiquen la razón o razones de ambos personajes para pedir o negar el deseo. El alumnado localiza la frase de cada interlocutor que sirva a la expresión de la razón abierta de cada uno, y se marca en el texto como razón $P$ (protagonista) o razón $A$ (antagonista). Se clasifican atendiendo a su tipología, y se anima a los estudiantes a ir extrayendo conclusiones sobre lo que esta traduce de la forma de ser de cada personaje. Después, se les plantea si existe otro tipo de razones (secreta o inconsciente) para el protagonista y/o el antagonista. En este punto del análisis suelen aparecer dificultades. Primero porque una razón secreta se expresa de forma indirecta por medio del subtexto, así que hay que detenerse a interpretar bien las palabras empleadas y localizar si hay en ellas alguna intención implícita. También porque en ocasiones una misma razón abierta se expresa de diferentes modos durante la escena, lo que no implica que se trate de distintas razones abiertas de un mismo personaje ni de la confesión de una secreta. Hay que clasificar todas ellas atendiendo también a su naturaleza y beneficiario.

Lo siguiente es la búsqueda de las estrategias de cada personaje. Se localiza la primera intervención que da inicio a cada una y se señalan en el texto como estrategia $P$ o estrategia $A$, según si esa línea de diálogo corresponde 
al protagonista o al antagonista. Se describe la estrategia mediante un verbo, por ejemplo 'amenazar', y se buscan las restantes intervenciones que desarrollen este plan. Se unirán los distintos diálogos con una llave al lado y se identificarán como estrategia $P$ 'amenazar' (por ejemplo). A continuación, se identifica y describe con un verbo la estrategia empleada por el personaje contrario como contraataque. Del mismo modo, se localiza si hay más de una frase que responda a la misma estrategia. Se señalan o agrupan al lado contrario. Si uno de ellos varía su táctica, entonces se identifica como estrategia $2 P$ 'mentir' (por ejemplo) y se observa si el otro personaje varía la anterior. Así sucesivamente hasta el final de la escena. Al término se les plantea quién ha logrado su objetivo de cambiar o mantener el statu quo, y también quién ha empleado la estrategia o estrategias más efectivas y qué podemos deducir de las empleadas por cada uno.

Se continúa buscando una frase que permita deducir el estado de ánimo de cada personaje y señalándola en el texto. Puede haber varios puntos donde este se deje ver. Se intenta evitar señalar frases que ya hayan sido empleadas para otras funciones ya detectadas.

Se pregunta sobre la relación social de los personajes, cosa que se conoce por la obra en general. A veces no hay una frase del texto que lo exprese porque ya se ha dicho en otro punto la historia. El siguiente paso es definir su relación emocional. Aquí se les pregunta qué supone el protagonista para el antagonista, y viceversa. Se debe hallar una frase donde se perciba esa valoración subjetiva que cada uno hace del otro en este punto de su arco dramático. Se señalan como relación emocional $P$ para $A$ o relación emocional A para $P$. Suelen expresarse de un modo sutil e implícito, lo que conlleva dificultades a la hora de interpretar el subtexto. Los estudiantes deben sintetizar del modo más escueto posible cómo ve un personaje al otro (como un niño, como un monstruo, como un tirano, etc.). Finalmente, 
se localiza una frase donde se perciba la relación con el lugar para cada uno de los personajes. Del mismo modo, tienen que sintetizar ese vínculo emocional con el espacio de la acción dramática para el protagonista y para el antagonista y reflexionar sobre si el contexto de la acción ha forzado la estrategia de los personajes.

El objetivo del análisis de obras preexistentes es que los estudiantes puedan apreciar que cada frase del guion de una escena de conflicto debe tener una función específica, que un diálogo parte de una planificación, que se estructura y que, aunque la conversación parece improvisada, su escritura no lo ha sido. Percibirán el efecto rítmico de este trabajo del diálogo, donde no hay frases accesorias por la distribución de funciones narrativas entre las distintas intervenciones, todas son útiles para la caracterización o para hacer avanzar la trama. También, apreciarán el recurso constante al subtexto para introducir de forma indirecta rasgos de caracterización del personaje en un diálogo sobre un tema concreto. Por supuesto, podrán ver cómo los rasgos de los personajes afloran en las palabras que escoge emplear durante una conversación, y que reflejan sus diferentes personalidades con respecto a sus motivaciones, estrategia, número de intervenciones, etc.

La realización de estos análisis de obras preexistentes también pretende que adquieran experiencia para el autoanálisis de sus creaciones. Así podrán valorar si han sacado el máximo partido a las palabras empleadas, si han recurrido convenientemente al subtexto, si hay intervenciones accesorias sin función narrativa, si los personajes actúan conforme a algún patrón que permita percibir una personalidad consistente y coherente durante la escena u obra, etc.

La experiencia didáctica termina con la realización de una práctica de creación de diálogos por parte de los estudiantes. En ella deben escribir 
una escena de conflicto que se sustente en el diálogo entre dos personajes. Por cada una de las intervenciones deben incluir entre corchetes la categoría de análisis que plasma, tal y como hicieron en el análisis grupal guiado. Además, se les solicita que indiquen el subtexto de cada línea de diálogo, emulando la traducción sintética que también se hacía en clase. Si además quieren incluir lo que cada frase permite deducir de la caracterización del personaje, también están invitados a ello. El propósito es que planifiquen de antemano la escena, y que a su vez la analicen una vez terminada. Con la obligatoriedad de incluir estos corchetes se les quiere hacer conscientes de la cantidad de información psicosocial que traducen sus diálogos, y de si estos están haciendo uso o no de un lenguaje indirecto.

El resultado de este ejercicio individual es una escena de diálogo donde cada una de las intervenciones tiene una única misión (que coincide con una de las categorías descritas) y donde la mayoría recurren al subtexto evitando que la conversación resulte demasiado explícita. Este trabajo de creación de subtexto y de traducción de distintas categorías conlleva la búsqueda de palabras muy precisas que dejen entrever las intenciones del guionista. Al apreciar cómo cada personaje se dirige hacia un objetivo diferente, por motivos diversos, con estrategias alternativas, etc., nos encontramos con que cada uno presenta un lenguaje diferente, lo que también ayuda a su individualización y caracterización.

\section{Valoración de los egresados}

La falta de difusión de metodologías sistemáticas en la escritura de diálogos se puede apreciar en que, antes de iniciar esta experiencia didáctica, apenas un $9 \%$ de los encuestados manejaba alguna técnica para crear diálogos y solo el $50 \%$ conocía consejos genéricos que guiaran su diseño. Esto resulta todavía más llamativo en el caso de los encuestados que cuentan con formación o 
experiencia previa en guion (59\%). De ellos solo un 12\% había aprendido alguna técnica con anterioridad, y en los cursos formativos precedentes solo se le había transmitido consejos genéricos a un 60\%.

El $84 \%$ de los encuestados considera que el aprendizaje de las categorías de análisis del método Layton y su utilidad para la escritura de diálogos le ayudó a escribir sus diálogos de forma más sintética. Ha ayudado a un 91\% de los encuestados a definir un porqué, una función para cada intervención y a no crearlas arbitrariamente. La metodología Layton también ha proporcionado al 94\% de los egresados mayor conciencia de que las intervenciones de los personajes deben traducir indirectamente sus rasgos psicosociales, mejorando su uso del subtexto y la necesidad de huir de las líneas de diálogo explicativas. Un 95\% considera este método adecuado para mejorar la caracterización de sus personajes al adecuarse mejor sus palabras al momento dramático en el que se encuentran y sus características. El 84\% considera que el método le ha permitido precisar más en los matices del lenguaje empleado por cada personaje, lo que favorece a su individualización. El mismo porcentaje de encuestados se muestra favorable a adecuar su escritura a esta metodología, no solo por su utilidad, sino también por considerar que, al emplear una técnica similar a la empleada por los actores, esto puede contribuir a un mejor resultado en el rodaje.

Se puede confirmar la utilidad de la experiencia didáctica para los encuestados dados los elevados porcentajes de satisfacción que se perciben en cada uno de los ítems consultados. Esto se corrobora al preguntar por su valoración de la actividad de creación de diálogos donde debían aplicar el aprendizaje de categorías del método Layton a la escritura de una escena de conflicto, destacando la función de cada intervención de los personajes y su subtexto. Al consultar qué aprendizaje reforzaron más durante la ejecución de la actividad, los egresados destacan que al escribir diálogos teniendo en 
cuenta el método Layton, han sido conscientes de que la conversación resulta más realista y al mismo tiempo más dramática si se planifica de antemano que cada frase o intervención tenga una función concreta. En segundo lugar, reconocen tener una mayor destreza para dejar ver la personalidad y subjetividad de los personajes por medio de un lenguaje connotativo en lugar de recurrir a intervenciones explicativas. En tercer lugar, recurrir al método durante la escritura ha contribuido a mejorar su competencia a la hora de escoger las palabras empleadas por cada personaje. Esto les permite caracterizarlos mejor e individualizarlos. Por último, se destacan aspectos como la utilidad de esta actividad como guía de iniciación a los diálogos, incidiendo en estructurarlos más adecuadamente o en ayudarles a que estos tengan mayor ritmo al carecer de intervenciones innecesarias.

La mayor muestra de la utilidad de esta metodología es que un $80 \%$ de los encuestados manifiesta seguir empleando este sistema cuando escribe diálogos, y que algunos de los egresados, docentes de guion, afirman transmitirla en sus clases. De la encuesta también se deducen puntos débiles de la experiencia didáctica: a un $4 \%$ les resultó una actividad y metodología "innecesariamente complicadas". Algunos egresados proponen como solución a esto realizar más de un ejercicio de aplicación de la metodología, porque consideran que hacerlo en una sola ocasión no permite fijar del todo el procedimiento. Uno de los encuestados propone una actividad didáctica complementaria que, en su opinión, ayudaría a los estudiantes a valorar en mayor medida la utilidad del sistema de escritura: crear un diálogo antes de conocer el método, y, tras las sesiones sobre las categorías y los análisis guiados, repetir ese mismo diálogo teniendo en cuenta los principios aprendidos. 


\section{Conclusión}

Ante la escasez de metodologías sistemáticas para facilitar la escritura de diálogos, adaptar el método Layton empleado por los actores para preparar su trabajo resulta de gran ayuda para los estudiantes de guion. Les permite valorar que pese a que las secuencias presentan conversaciones que parecen improvisadas, sus diálogos han sido muy trabajados, diseñados específicamente para traducir una gran cantidad de información psicosocial de los personajes involucrados mientras estos hablan sobre otro tema. Esto les hace conscientes de la necesidad de planificar los diálogos, definiendo a priori una serie de datos de los personajes que han de deducirse de sus diferentes intervenciones. También que deben partir del punto del arco dramático en el que se halla cada uno, puesto que condicionará su actitud en la escena y las palabras que empleen en ella.

A la hora de escribir, este sistema les hace conscientes de la necesidad de distribuir estos datos entre las intervenciones, y de hacerlo de modo indirecto, mediante matices del habla de cada interlocutor que permitan interpretar aspectos íntimos de estos, de su estado o el de su relación en el momento de la escena. El autoanálisis posterior les permitirá valorar si las palabras empleadas por cada personaje permiten deducir su forma de ser, su estado o su evolución, y si esto se hace por medio de un lenguaje directo o subtextual. También, podrán valorar si en su diálogo existen intervenciones redundantes, accesorias o si, idealmente, cada una traduce una de las funciones narrativas deseables a la escena.

El único riesgo del empleo de esta metodología es caer, cuando aún no se domina bien, en escribir diálogos demasiado opacos, difíciles de interpretar y que carezcan de esa necesaria naturalidad, organicidad y falsa sensación de 
improvisación que deben prevalecer en las escenas. Se recomienda realizar muchos análisis de obras ajenas antes de aplicarla al trabajo de escritura propio.

Con este artículo no se pretende trasladar la necesidad de aplicar este método exhaustivamente a la creación de guiones, pero sí comprenderla y adquirir práctica en ella. Hacerlo permite "pensar la escena", considerarla un mecanismo que, para que funcione, hay que diseñar cuidadosamente cada parte a priori. Dominar el método Layton contribuirá a encontrar con agilidad la forma específica del complejo magma de emociones o ideas que subyacen a las palabras de los personajes.

\section{Referencias}

Aristóteles. (1999). Poética (Trad. V. García). Gredos.

Bednarek, M. (2015). An overview of the linguistics of screenwriting and its interdisciplinary connections, with special focus on dialogue in episodic television. Journal of Screenwriting, 6(2), 221-238. https://doi.org/10.1386/josc.6.2.221_1

Brook, V. (2009). Convergent Ethnicity and the Neo-platoon Show. Television \& New Media, 10(4), 331-353. https://doi.org/10.1177/1527476409334021

Capuzza, J. C., \& Spencer, L. G. (2017). Regressing, Progressing, or Transgressing on the Small Screen? Transgender Characters on U.S. Scripted Television Series. Communication Quarterly, 65(2), 214-230. https://doi.org/10.1080/01463373.2016.1221438

Casetti, F., \& Di Chio, F. (2007). Cómo analizar un film. Paidós.

Chion, M. (2009). Cómo se escribe un guion. Cátedra.

Conor, B. (2014). Gurus and oscar winners: How-to screenwriting manuals in the new cultural economy. Television and New Media, 15(2), 121-138. https://doi. org/10.1177/1527476412452798

Estrin, M. (2002). Orson Welles interviews. University Press Mississippi.

Field, S. (2005). Screenplay. The Foundations of Screenwriting. Random House. 
Greens, R. (2017). Character over concept: Writing dialogue in search of story. Journal of Screenwriting, 8(1), 39-54. https://doi.org/10.1386/josc.8.1.39_1

Hoff, J. A. (2016). Gender, Genre, And "Quality": Television From 1951-2013. Electronic Theses and Dissertations.

Imre, A. (2012). Adventures in Early Socialist Television Edutainment. Journal of Popular Film and Television, 40(3), 119-130. https://doi.org/10.1080/01956051.2012.697790

Jaagola, K. (2019). Seriality in transmedia storytelling: A case study of Halo. Ekphrasis, 22(2), 152-168. https://doi.org/10.24193/ekphrasis.22.9

Kozloff, S. (2000). Overhearing Film Dialogue. University of California Press.

Lavandier, Y. (2011). La dramaturgie. Le Colwn et I'Enfant.

Layton, W. (2016). ¿Por qué?: Trampolín del actor. Fundamentos.

Loftin, G. (2018). Writing-for-the-cut: What can screenwriters learn from film editors about storytelling? Journal of Screenwriting, 9(1), 85-102. https://doi.org/10.1386/josc.9.1.85_1

McKee, R. (2013). El guion. ALBA.

McKee, R. (2018). El diálogo: El arte de hablar en la página, la escena y la pantalla. ALBA.

Mittell, J. (2010). Previously On: Prime Time Serials and the Mechanics of Memory. In M. Grishakova \& M.-L. Ryan (Eds.), Intermediality and Storytelling (pp. 78-98). De Gruyter. https://doi.org/10.1515/9783110237740.78

Mittell, J. (2015). Complex TV: The Poetics of Contemporary Television Storytelling. NYU Press.

Moulton, E. (2019). Crafting an 'authentic' monster: Dialogue, genre and ethical questions in Mindhunter (2017). Journal of Screenwriting, 10(2), 195-212. https://doi.org/10.1386/ josc.10.2.195_1

Pérez, M. M. (2009). La figura de Constantin Stanislawski y su importancia y repercusión en las técnicas interpretativas contemporáneas. Danzaratte: Revista del Conservatiorio Superior de Danza de Málaga, 5, 81-87.

Piazza, R. (2010). Voice-over and self-narrative in film: A multimodal analysis of Antonioni's When Love Fails (Tentato Suicidio). Language and Literature, 19(2), 173-195. https://doi. org/10.1177/0963947010362911 
Richardson, K. (2010). Television Dramatic Dialogue. In Television Dramatic Dialogue. Oxford University Press. https://doi.org/10.1093/acprof:oso/9780195374056.001.0001

Ryan, M.-L. (1991). Possible Worlds, Artificial Intelligence, and Narrative Theory. Indiana University Press.

Seger, L. (2017). Writing subtext. What lies behind. Michael Wiese Productions.

Seger, L. (2019). Cómo llegar a ser un guionista excelente. RIALP.

Snyder, B. (2018). ¡Salva al gato! ALBA.

Truby, J. (2014). Anatomía del guión. El arte de narrar en 22 pasos. ALBA.

Winter, R. (2016). "All Happy Families": The Sopranos and Television Culture in the Twenty-First Century. Frontiers of Literary Studies in China, 10(3), 474-494. https://doi.org/10.3868/s010005-016-0028-3

Cómo citar: Nevado, I., Fernández-Ramírez, L. y Naranjo, A. (2022). Lo que los personajes tienen que decir. La creación de diálogos mediante la metodología de William Layton. Revista KEPES, 19(25), 107-133. https://doi.org/10.17151/kepes.2022.19.25.5 